\title{
The Intergenerational Transmission of The Father's Pro-Social Behavior: The Mediating Effect of The Father's Marital Satisfaction and The Parents' Support for Co-parenting
}

\author{
Liping Wen \\ 1. Institute of Psychology, Chinese \\ Academy of Sciences, Beijing, \\ P.R.China 100101; 2. Department of \\ Psychology, University of Chinese \\ Academy of Sciences, Beijing, \\ P.R.China 100049 \\ lipingwenxiaoxiao@126.com
}

\author{
Ting Zhou \\ Department of Medical Psychology, \\ School of Health Humanities, Peking \\ University, Beijing, P.R.China 100191 \\ zhouting.92@bjmu.edu.cn
}

\author{
Zheng Huang \\ 1. Institute of Psychology, Chinese \\ Academy of Sciences, Beijing, \\ P.R.China 100101; 2. Department of \\ Psychology, University of Chinese \\ Academy of Sciences, Beijing, \\ P.R.China 100049 \\ huangz@psych.ac.cn
}

\begin{abstract}
Based on the family ecological system theory, this paper explores the driving mechanism of the fathers'pro-social behavior and the children's pro-social behavior, which can be achieved by analyzing two factors : (1)fathers' marital satisfaction ,and(2)parents' support for co-parenting.In this paper,we investigated 670 fathers of children aged between 3 and 6 who were raised mainly by their parents alone or collaborating with others and collected the corresponding sample data. The data is analyzed by the "structural equation model" and "bootstrap method". Our findings prove that there were strong positive correlations between the fathers' pro-social behavior with the children's pro-social behavior, between which fathers' marital satisfaction and parents' support for co-parenting play a chain mediating role.
\end{abstract}

\section{CCS CONCEPTS}

- Applied computing; • Law, social and behavioral sciences; - Psychology;

\section{KEYWORDS}

Family Ecological System Theory, Father's Pro-social Behavior, Father's Marital Satisfaction, Parents' Support for Co-parenting, Children's Pro-social Behavior

\section{ACM Reference Format:}

Liping Wen, Ting Zhou, and Zheng Huang. 2021. The Intergenerational Transmission of The Father's Pro-Social Behavior: The Mediating Effect of The Father's Marital Satisfaction and The Parents' Support for Co-parenting. In The 2021 12th International Conference on E-business, Management and Economics (ICEME 2021), fuly 17-19, 2021, Beijing, China. ACM, New York, NY, USA, 7 pages. https://doi.org/10.1145/3481127.3481133

Permission to make digital or hard copies of all or part of this work for personal or classroom use is granted without fee provided that copies are not made or distributed for profit or commercial advantage and that copies bear this notice and the full citation on the first page. Copyrights for components of this work owned by others than ACM must be honored. Abstracting with credit is permitted. To copy otherwise, or republish, to post on servers or to redistribute to lists, requires prior specific permission and/or a fee. Request permissions from permissions@acm.org.

ICEME 2021, fuly 17-19, 2021, Beijing, China

(C) 2021 Association for Computing Machinery.

ACM ISBN 978-1-4503-9006-4/21/07 ..\$15.00

https://doi.org/10.1145/3481127.3481133

\section{INTRODUCTION}

Early childhood is an important period for the development of pro-social behavior1 [1]. Pro-social behavior is an integral part of human life, has important implications for social development, and plays an important role in successful social interactions and peer acceptance [2-5]. The father, as a member of the family, cannot be replaced by the mother in the family [6].Despite the profound impact of pro-social behavior on young children's development, much of the previous research on pro-social behavior in young children has been conducted from the mother's perspective. Previous findings suggest that father care is associated with child behavior [7] and that treatment outcomes for child behavior problems improve when fathers are involved in treatment [8]. Although fathers in numerous families around the globe barely take on the day-to-day care of their infants and young children, most men do have a profound developmental impact on the lives of their children [9] .This influence - like that of the child's mother - needs to be seen and understood in the context of the parenting efforts of each responsible adult in the child's family [10].As a result, a growing body of research has begun to focus on the influence of fathers on young children's pro-social behavior.

In recent years, a number of scholars have conducted extensive research on the factors and mechanisms that influence young children's pro-social behavior. Family ecological system theory states that for young children, the family is the earliest performer and the basic performer of socialization for young children, and is the microsystem that has the greatest influence on them [11]. The family consists of several subsystems such as the father subsystem, mother subsystem, child subsystem, couple subsystem, parent subsystem, parent-child subsystem, and sibling subsystem [12] . Therefore, more research is necessary to investigate the joint mechanisms of the effects of fathers' pro-social behavior on young children's pro-social behavior.

\section{THEORY AND HYPOTHESIS}

\subsection{Pro-social Behavior}

Early childhood is an important period for the development of prosocial behavior, and the term "prosocial behavior" was first mentioned by Weisbegr in 1972 in "An Examination of Socially Positive 
Forms" to represent all behaviors that are opposed to negative behaviors such as aggression [13].Over the decades, many scholars have refined the definition, examining and explaining, to varying degrees, the goals of the behavior, how the recipient is influenced, the intended goals of the behavior, and how the donor is influenced.Throughout the definition of pro-social behavior by scholars, there is a general consensus on the following: first, the behavior is intended to benefit others; second, it is in line with social expectations and requirements; third, it is not only one thing, but also includes a variety of responses related to the common core tendency to help others together; fourth, helping, sharing, comforting and cooperating are often cited as typical pro-social behaviors.

\subsection{Marital Satisfaction}

Marital satisfaction first originated from the study of marital quality, and was first mentioned by the American sociologist Hamilton (1929) in his book "The Study of Marriage" and defined it as a married couple's subjective feeling and assessment of the degree of satisfaction with their marital relationship. After more than 80 years of research development, three major schools of thought have emerged among researchers regarding multiple definitions of marital satisfaction. In the personal perception school, marital satisfaction is used as a measure of marital quality, indicating married people's subjective perceptions and experiences of marriage. In the accommodation school of thought, marital satisfaction is one of the various external manifestations of marital quality, which they view as objective in nature, embodied in the specific characteristics of the couple's relationship and the external manifestations of those characteristics [14]. By the 1990s, researchers began to consider marital quality to include not only marital satisfaction but also marital adjustment, grasped from both subjective perceptions and objective descriptions. The operational definition of marital satisfaction in this study is based on the individual perception school of thought, which defines marital satisfaction as a subjective assessment of the spouse's or partner's satisfaction with their perceived marital life in a marital relationship.

\subsection{Parents' Support For Co-parenting}

The concept of coparenting was first developed by Minuchin in family structure theory. Coparenting refers to the collaborative behavior of parents or other acknowledgments of parenting responsibilities in the parenting of children [15]. Previous research has categorized co-parenting as supportive and conflictual parenting. Supportive co-parenting is a parenting style in which only one parent makes efforts toward parenting while the other parent opposes or interferes with one parent's parenting [16] .Co-parenting behavior is an evolution of parenting behavior, and co-parenting is a family ecosystem in which the father subsystem interacts with the mother subsystem and the two interact together with the child subsystem, with all three sharing family elements.In this study, we only explore the type of supportive co-parenting.

\subsection{Intergenerational Transmission Of Paternal Pro-social Behavior}

The central idea of sociobiological theory is that genes cause individuals to behave in a certain way, thereby increasing the likelihood that these genes will be replicated in offspring [17] . The role of genetics in prosocial behavior is confirmed by findings from early twin and adoption studies: a longitudinal study of 9,349 twin pairs by Knafo and Plomin found that the heritability of prosocial behavior was approximately $30 \%$ [18]; a study of 3.5-year-old twins by Knafo and Israel Knafo and Israel estimated a moderate contribution of genetic factors to individual differences in empathy [19]. Although previous studies have confirmed the correlation between fathers' prosocial behavior and young children's prosocial behavior, the contribution of genetic factors is moderate. In addition to genetics, the environment also influences young children's pro-social behavior. Previous research on anti-prosocial behaviors such as violence [20], corporal punishment [21], abuse [22], and other anti-prosocial behaviors has demonstrated intergenerational transmission of fathers' and children's behaviors. Some studies have also demonstrated the existence of intergenerational transmission of pro-social behaviors: e.g., helping behaviors, volunteering behaviors [23].The above studies were conducted in Western cultures, and the phenomenon of intergenerational transmission of behaviors exists not only in Western cultures but also in China. Therefore, the following hypothesis is put forward:

H1: father prosocial behavior positively predicts young children's prosocial behavior and intergenerational transmission exists.

\subsection{The Mediating Role of Parental Support for Co-parenting}

In the process of pro-social behavior formation and development, young children must interact fully and actively with their home environment, and the behavior of parents in the parenting process is important. Cooperative behaviors are an important type of prosocial behavior, and cooperation produces synergistic effects [24]. Parental support for co-parenting refers to the parenting alliance that develops as a result of collaborative, affirming, and supportive processes between parents in the co-parenting of their children [25]. And parental support co-parenting can be understood as mutually coordinated behaviors of parents for the common goal of educating their children. Thus, a cooperative co-parenting relationship is more likely to develop if fathers have high levels of pro-social behavior. Parental alliances function effectively when parents cooperate to provide a family environment that conveys to children solidarity among parenting, a consistent and predictable set of rules and standards (whether or not children live in a family). Thus, supportive co-parenting by parents has a direct predictive effect on children's pro-social behavior, and conversely, conflict between parents inhibits children's pro-social behavior [26].In summary, it is likely that fathers' pro-social behavior enhances young children's pro-social behavior by increasing the level of parental support for co-parenting.Therefore, the following hypothesis is put forward:

$\mathrm{H} 2$ : to examine the role of parental support co-parenting as a mediating variable in the relationship between fathers' pro-social behavior and toddlers' pro-social behavior.

\subsection{Mediating Role of Fathers' Marital Satisfaction}

In addition to fathers' pro-social behavior, what other factors influence parental co-parenting? Of all the influences on co-parenting 


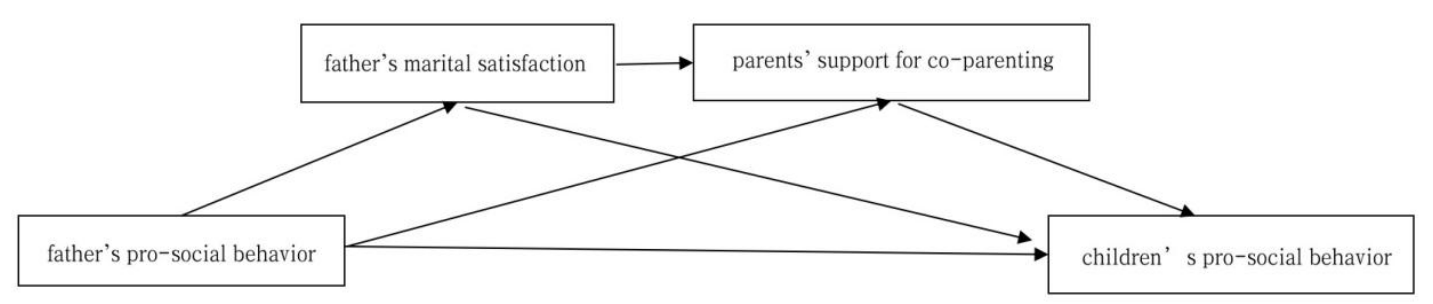

Figure 1: The hypothesis framework

that have been explored, marital quality is the most effective predictor [27]. Marital satisfaction reflects the relationship and quality of the marriage, and fathers' marital satisfaction reflects their subjective perceptions of the marriage. Couples in well-functioning marriages create positive parental partnerships [28] , and negative emotional expressions are typically associated with poorer marital interactions and lower marital satisfaction, whereas positive expressions are associated with more positive marital interactions and higher marital satisfaction [29]. Thus, fathers' perceptions and ratings of marital satisfaction influence the level of co-parenting. Therefore, the following hypothesis is put forward:

H3: It is proposed to examine the mediating role of fathers' marital satisfaction in the relationship between fathers' pro-social behaviors and young children's pro-social behaviors.

\subsection{The Chain Mediating Role of Fathers' Marital Satisfaction and Parental Support for Co-parenting}

If both fathers' marital satisfaction and co-parenting support mediate the relationship between fathers' pro-social behavior and young children's pro-social behavior, then the effects of both may not be parallel, but may affect young children's pro-social behavior in a "serial" manner, as suggested by the spillover-pothesis. The spillover-pothesis suggests that the emotions or behaviors of one of the interacting parties in one subsystem of the family will influence the emotions or behaviors of the other party in the other subsystem [30]. In the present study, i.e., the emotional experience of marriage exhibited by the father in the parent subsystem affects the emotional experience of co-parenting in the couple subsystem. Therefore, it is reasonable to assume that the emotions, feelings and behaviors expressed in the parent subsystem are generated by the marriage subsystem and migrate to co-parenting in the parent subsystem through the father's marital satisfaction in the couple subsystem. Therefore, the following hypothesis is put forward:

H4: Father marital satisfaction and parental support for coparenting play a chain mediating role in fathers' pro-social behavior and young children's pro-social behavior.

In conclusion, the theoretical model of our study is shown in Figure 1.

\section{METHODS}

\subsection{Subjects}

The study used a whole-group sampling method with 670 fathers of young children whose primary caregivers were parents or coparents from eight kindergartens in China as subjects. The age range of the children in the participating families was 3-6 years, with a mean age of $5.142 \pm 1.109$, and the subjective economic status (SSS) of the families was $13.003 \pm 3.046$. The specific demographic variables are shown in Table 1.

\subsection{Measures}

The measurement tables used in this paper are mature scales that have been empirically tested.

3.2.1 Demographic Variables. These included gender, age, family structure, and primary parenting elders.

3.2.2 Pro-social Behavior Scale for Young Children. The Empathic, prosocial response to another's distress scale, developed by Kochanska et al. and translated and revised by Zhang Zhen,The scale consists of 13 items and is scored on a 7-point Likert scale, with 1 being "not at all" and 7 being "fully", and the mean of the child's total score on the 13 items is used as an indicator of the child's prosocial behavior. The higher the score, the higher the pro-social behavior of the child. The revised scale showed stable reliability, and the Cronbach alpha coefficient of the scale in this study was 0.798 .

3.2.3 Father's Pro-social Behavior Questionnaire. The Prosocial Tendencies Measure (PTM), developed by American psychologists Carlo and Radall, and translated and revised from Wenjun, was selected. The scale consists of 23 items in 6 dimensions: overt, anonymous, altruistic, dependent, emotional, and urgent, and is scored on a 5-point Likert scale, with 1 being "not at all" and 5 being "fully". The revised Pro-Social Tendency Questionnaire was tested to have good reliability and validity, and the Cronbach alpha coefficient of the scale was 0.926 in this study.

3.2.4 Father's Marital Satisfaction Scale. The marital satisfaction subscale of the marital quality questionnaire (ENRICH), developed by Olson and revised and integrated by Li Lingjiang, was selected (Olson quality of marriage questionnaire), was applied to married couples to understand fathers' perceptions of marital quality. The scale consists of 10 items, each of which is rated on a 5-point scale, with five questions, $2,4,6,7$, and 10, being scored positively, and 
Table 1: Description of the statistical information of the sample $(\mathrm{N}=670)$

\begin{tabular}{llll}
\hline Statistical variables & Item & Number of people & Ratio \\
\hline Gender of young children & Male & 366 & $54.63 \%$ \\
& Female & 304 & $45.37 \%$ \\
Toddler's age & 3 & 44 & $9.27 \%$ \\
& 4 & 145 & $21.64 \%$ \\
& 5 & 378 & $26.57 \%$ \\
Family structure & 6 & 463 & $45.22 \%$ \\
& Three and more generations & 19 & $69.25 \%$ \\
Primary parenting elders & Family of three & 187 & $2.84 \%$ \\
& Families with two or more children & 318 & $27.91 \%$ \\
& Parents & 352 & $47.46 \%$ \\
& Parents raising together with others & $52.54 \%$ \\
\hline
\end{tabular}

five questions, $1,3,5,8,9$, being scored negatively, with scores obtained by summing the scores of the items they represent, with higher scores representing higher satisfaction with their marriage. In this study, the Cronbach alpha coefficient of the scale was 0.756 .

3.2.5 Parental Support Co-parenting Scale. The co-parenting scale developed by Stright and Bale, and revised by Chang Liu and Xinchun $\mathrm{Wu}$, was selected in order to understand parental interaction in the process of parenting their children. The scale was divided into two dimensions, parental support for co-parenting and parental non-support for co-parenting, of which the parental support for co-parenting dimension was selected for this study, which consisted of 7 items on a Likert 5 scale, with 1 representing "never" and 5 representing "always "The higher the score, the higher the level of parental support for co-parenting. In this study, the Cronbach alpha coefficient of the scale was 0.849 .

3.2.6 Father's Subjective Socioeconomic Status Scale. The adult version of the MacArthur Scale of Subjective Social Status developed by Adler et al. was used in this study, and the Chinese version of the Subjective Socioeconomic Status Scale translated by Chen Yuning et al. the Subjective Socioeconomic Status Scale CSSS). The scale has 2 entries, entry 1 (social status) is linked to the traditional SES indicator and is used by individuals to assess their position in the overall social environment. Item 2 (Community Status) is related to the individual's living environment and is used to assess one's position in the community. Each item is scored on a scale of 1 to 10 , with a total score of 20 . A lower score indicates a lower subjective socioeconomic status, while a higher score indicates a higher subjective socioeconomic status. The scores of this scale were used as control variables in this study.

\section{EMPIRICAL ANALYSIS}

\subsection{Common Method Bias}

In this study, the scales were all assessed by the fathers of the young children, and in order to reduce potential bias, the data collection process was controlled in terms of measurement procedures, such as the use of anonymous methods of measurement and the use of reverse questions for some items. In terms of statistical control, after data collection, we used Harman's one-way test[31], to put all variables such as young children's pro-social behavior, adults' pro-social tendencies, and marital satisfaction into one exploratory factor analysis to test the results of the unrotated factor analysis. It was found that the factor analysis extracted a total of 10 factors with characteristic roots greater than 1, which cumulatively explained $58.217 \%$ of the variance, and the variance explained by the first common factor was $23.068 \%$, which did not reach the critical value criterion of $40 \%$; therefore, there was no significant common method bias in the data of this study.

\subsection{Test for Differences in Each Variable On Demographic Variables}

A multivariate ANOVA was used to test for differences in each variable on demographic variables, and the results are shown in the table (see Table 2 on the next page).

No significant differences were found between children's ages and family structures for father's pro-social tendencies, father's marital satisfaction, support for co-parenting, and children's pro-social behavior. There were no significant differences in the pro-social behavior of children by primary parenting elder and child gender. There was a significant difference between the gender of the children and the pro-social behavior of the children. The mean of boys (5.04) is significantly lower than the mean of girls (5.15), as shown by the 0.05 level of significance $(F=4.496, p=0.034)$ and the specific comparison differences. The primary parenting elders showed a 0.01 level of significance $(\mathrm{F}=9.473, \mathrm{p}=0.002)$ for the pro-social behavior of young children, as well as specific contrasting differences that show that the mean of parents (5.01), would be significantly lower than the mean of parents and others co-parenting (5.16).

\subsection{Descriptive Statistics and Correlation}

The means, standard deviations, and correlation coefficients of all variables are shown in Table 3. The results of the correlation analysis between fathers' pro-social orientation, fathers' marital satisfaction, co-parenting and young children's pro-social behavior showed significant correlations between the variables. 
Table 2: Comparison of Differences among Variables on Demographic Variables

\begin{tabular}{|c|c|c|c|c|c|}
\hline & & $\begin{array}{l}\text { father's pro-social } \\
\text { behavior }\end{array}$ & $\begin{array}{l}\text { father's marital } \\
\text { satisfaction }\end{array}$ & $\begin{array}{l}\text { parents' support for } \\
\text { co-parenting }\end{array}$ & $\begin{array}{l}\text { children's pro-social } \\
\text { behavior }\end{array}$ \\
\hline \multicolumn{2}{|l|}{ Overall } & $3.273 \pm 0.573$ & $36.976 \pm 5.866$ & $3.760 \pm 0.690$ & $5.090 \pm 0.645$ \\
\hline \multirow{2}{*}{$\begin{array}{l}\text { Gender of } \\
\text { young children }\end{array}$} & Male & $3.25 \pm 0.56$ & $37.25 \pm 5.90$ & $3.84 \pm 0.74$ & $5.04 \pm 0.66$ \\
\hline & Female & $3.30 \pm 0.59$ & $36.65 \pm 5.82$ & $3.60 \pm 0.55$ & $5.15 \pm 0.62$ \\
\hline \multicolumn{2}{|c|}{$\mathrm{F}$} & 1.252 & 1.743 & 1.766 & $4.496^{*}$ \\
\hline \multirow[t]{4}{*}{ Toddler's age } & 3 & $3.27 \pm 0.47$ & $37.18 \pm 5.63$ & $4.05 \pm 0.58$ & $4.96 \pm 0.63$ \\
\hline & 4 & $3.27 \pm 0.54$ & $37.66 \pm 6.08$ & $3.85 \pm 0.40$ & $5.05 \pm 0.71$ \\
\hline & 5 & $3.27 \pm 0.57$ & $36.51 \pm 5.91$ & $3.70 \pm 1.02$ & $5.08 \pm 0.57$ \\
\hline & 6 & $3.28 \pm 0.61$ & $36.89 \pm 5.76$ & $3.74 \pm 0.64$ & $5.13 \pm 0.66$ \\
\hline $\mathrm{F}$ & & 0.009 & 1.073 & 0.210 & 1.223 \\
\hline \multirow[t]{3}{*}{$\begin{array}{l}\text { Family } \\
\text { structure }\end{array}$} & $\begin{array}{l}\text { Three and more } \\
\text { generations }\end{array}$ & $3.29 \pm 0.56$ & $37.13 \pm 5.97$ & $3.74 \pm 0.70$ & $5.11 \pm 0.63$ \\
\hline & Family of three & $3.27 \pm 0.52$ & $35.84 \pm 6.53$ & $3.43 \pm 0.61$ & $5.03 \pm 0.71$ \\
\hline & $\begin{array}{l}\text { Families with two } \\
\text { or more children }\end{array}$ & $3.24 \pm 0.61$ & $36.71 \pm 5.54$ & $3.92 \pm 0.69$ & $5.04 \pm 0.68$ \\
\hline $\mathrm{F}$ & & 0.429 & 0.715 & 0.546 & 0.851 \\
\hline Primary & Parents & $3.26 \pm 0.60$ & $36.86 \pm 5.66$ & $3.69 \pm 0.70$ & $5.01 \pm 0.64$ \\
\hline $\begin{array}{l}\text { parenting } \\
\text { elders }\end{array}$ & $\begin{array}{l}\text { Parents raising } \\
\text { together with } \\
\text { others }\end{array}$ & $3.29 \pm 0.55$ & $37.08 \pm 6.06$ & $3.81 \pm 0.69$ & $5.16 \pm 0.64$ \\
\hline $\mathrm{F}$ & & 0.338 & 0.230 & 0.371 & $9.473^{* *}$ \\
\hline
\end{tabular}

Note: ${ }^{*} \mathrm{P}<0.05,{ }^{* *} \mathrm{P}<0.01,{ }^{* * *} \mathrm{P}<0.001$ Same below

Table 3: Descriptive Statistics and Correlations of the Variables

\begin{tabular}{llllll}
\hline & $\mathrm{M} \pm \mathrm{SD}$ & 1 & 2 & 3 & 4 \\
\hline 1 father's pro-social behavior & $3.273 \pm 0.573$ & 1 & & & \\
2 father's marital satisfaction & $36.976 \pm 5.866$ & $0.245^{* *}$ & 1 & $0.570^{* *}$ & 1 \\
3 parents' support for co-parenting & $3.760 \pm 0.690$ & $0.361^{* *}$ & $0.239^{* *}$ & $0.315^{* *}$ & 1 \\
4 children's pro-social behavior & $5.090 \pm 0.645$ & $0.407^{* *}$ & 1 \\
\hline
\end{tabular}

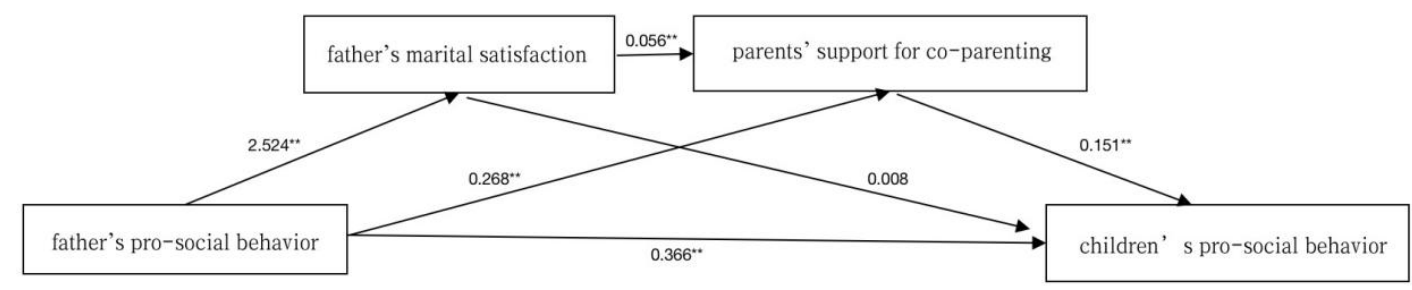

Figure 2: Structural Equation Model

\subsection{Structural Equation Model Testing}

As shown in Figure 2, the direct predictive effect of fathers' prosocial behavior on young children's pro-social behavior was significant $\left(\mathrm{B}=0.366^{* *}, \mathrm{p}<0.01\right)$, and hypothesis 1 holds.

Father's pro-social behavior positively predicted father's marital satisfaction $(\mathrm{B}=2.396, \mathrm{p}<0.01)$ and parental support for co-parenting $(\mathrm{B}=0.268, \mathrm{p}<0.01)$; father's marital satisfaction positively predicted parental support for co-parenting $(B=0.056, p<0.01)$; father's marital satisfaction and parental support for co-parenting positively predicted toddler's pro-social behavior, respectively $(B=0.008 ; B=0.151$, $\mathrm{p}<0.01)$. 
Table 4: Testing for Mediation Effect

\begin{tabular}{llll}
\hline & Effect & BootLLCI & BootULCI \\
\hline Direct Effect & 0.366 & 0.284 & 0.448 \\
FPB $\rightarrow$ PSC $\rightarrow$ CPB & 0.036 & 0.017 & 0.032 \\
FPB $\rightarrow$ FMS $\rightarrow$ CPB & 0.020 & 0.022 & 0.046 \\
FPB $\rightarrow$ FMS $\rightarrow$ PSC $\rightarrow$ CPB & 0.020 & 0.008 & 0.018 \\
Total Effect & 0.442 & 0.364 & 0.521 \\
\hline
\end{tabular}

\subsection{Testing for Multiple Chain Mediation Effect}

Mediating effects were further analyzed using Preacher and Hayes' Bootstrap test for mediating effects[32], after controlling for demographic variables such as gender and age, family structure, primary parenting elders, and family SSS, a mediating effect study was conducted with father's pro-social behavior as the independent variable and toddler's pro-social behavior as the dependent variable with a sampling size of 500 to further examine the mediating effect of fathers' marital satisfaction and co-parenting between fathers' prosocial behavior and toddlers' pro-social behavior. The results are shown in Table 4 the direct effect of fathers' pro-social behavior on toddlers' pro-social behavior was 0.366 with $95 \%$ confidence interval $[0.021,0.250]$, indicating a significant direct effect and valid $\mathrm{H} 1$; the mediating effect of parents' support for co- The mediating effect of parenting was 0.036 with $95 \%$ confidence interval [0.017,0.032], indicating a significant mediating effect and validity of $\mathrm{H} 2$; the mediating effect of fathers' marital satisfaction was 0.020 with $95 \%$ confidence interval [0.022,0.046], indicating a significant mediating effect and valid $\mathrm{H} 3$; the chain mediating effect of fathers' marital satisfaction and parental support for co-parenting on fathers' prosocial behavior and toddlers' pro-social behavior is 0.442 with $95 \%$ confidence interval [0.364,0.421], indicating a chain mediating effect of the above two variables, and $\mathrm{H} 4$ holds.

\section{CONCLUSION}

\subsection{Study Results}

Our study draws four conclusions as follow:

The gender of the child and the primary caregiver showed significant differences on the pro-social behavior of the child.

Fathers' pro-social behavior positively predicted young children's pro-social behavior, and there was intergenerational transmission.

Parental support for co-parenting partially mediated the relationship between fathers' pro-social behavior and toddlers' pro-social behavior.

Similar to parental support co-parenting, fathers' marital satisfaction also partially mediated the effect. In addition, the mediating effect of fathers' marital satisfaction was lower than that of parental support co-parenting.

Fathers' marital satisfaction and parental support co-parenting play a chain mediating role in fathers' pro-social behaviors and young children's pro-social behaviors.

\subsection{Theoretical Contributions}

Theoretically, we first enriched the research on the antecedents of pro-social behavior in young children. While previous studies have focused more on the influence of mothers on young children's pro-social behavior, this paper delves into the mechanisms of fathers' pro-social behavior on young children's pro-social behavior. The role of fathers cannot be ignored for a family, and therefore, exploring the role of fathers in young children's prosocial behavior has great empirical value for family education. Second, previous studies have provided evidence for a linear mediating relationship between fathers' pro-social behavior, fathers' marital satisfaction, parental support co-parenting, and toddlers' pro-social behavior, but no previous studies have addressed the effects of these four variables. This paper constructs a chain mediation model between fathers' pro-social behavior, fathers' marital satisfaction, parental support co-parenting, and toddlers' pro-social behavior to systematically reveal the effects of fathers' marital This paper constructs a chain mediation model among father's pro-social behavior, father's marital satisfaction, parental support for co-parenting, and young children's pro-social behavior, systematically revealing the mediating role of father's marital satisfaction and parental support for co-parenting, which is an extension of previous studies.

\subsection{Educational Insights}

5.3.1 Pay attention to fathers' role models and respond positively to young children's pro-social behaviors. Fathers' words and actions can have an important influence on their children. The most convincing education is to influence children with their own words and actions. Young children are good at imitation, and observing positive role models helps promote pro-social behaviors in young children. Therefore, fathers should set an example by cooperating more with family members and participating in activities such as charity and social volunteering, both at home and in the community, to establish a pro-social role model image for their children, so that young children can intentionally or unintentionally imitate, which can effectively promote the formation and development of pro-social behavior in young children. In addition to teaching children by example, children can also be taught by word. They can be led to read books on pro-social behavior, learn children's songs, or set up certain social situations to provide children with objects to imitate. At the same time, after children have made pro-social behaviors, they should be praised and rewarded in time to positively reinforce their pro-social behaviors and promote the virtuous cycle of pro-social behaviors. 
5.3.2 Create a good family atmosphere and improve the quality of collaborative parenting. Early childhood is an important period for the development of individual pro-social behavior, and the family environment has a great influence on the development of young children. A positive early growth environment is conducive to shaping physically and mentally healthy children, For young children, if they often see that conflicts between parents cannot be well negotiated and resolved, they also cannot be well negotiated and resolved in their interactions with others due to their lack of experience and guidance. Therefore, parents should work together to run their marriage, establish an equal relationship as husband and wife, understand, respect and help each other, create a harmonious family atmosphere, support and encourage each other in life and work, and improve the quality of their marriage. In the process of parenting their children, they should respect each other, negotiate together, agree on parenting cognition and behavior, support each other's parenting behavior, provide a good family atmosphere for the development of young children's pro-social behavior, let children grow up in an environment full of love and care, and parents effectively help the formation and development of young children's pro-social behavior.

\subsection{Research limitations and Future Prospects}

First, the measurement of each variable in this study used only data collected from the father's side and did not involve the mother and other family members; it is desirable to have multiple sources of data for a family system study; therefore, future studies could have more family members collecting data. Second, only fathers' self-reports were available in this study, although common method bias showed that there were not many method effects, and without the support of research methods such as experimental methods, the results might be biased, so combining experimental methods to collect behavioral data from young children and parents would help us to explore the relationship more accurately. Finally, based on the results of this study, we suggest relevant suggestions for future research: to strengthen the attention and research on the mechanisms of pro-social behavior formation under the family ecosystem, such as studying the mechanisms of the role of fathers' and mothers' pro-social behavior on toddlers' pro-social behavior; and the mechanisms of the role of other family systems on toddlers' pro-social behavior.

\section{REFERENCES}

[1] HAY D F , PAYNE A , CHADWICK A . Peer relations in childhood[J]. Journal of Child Psychology \& Psychiatry, 2010, 45(1):84-108.

[2] DEKOVIC M , JANSSENS J M . Parents' child-rearing style and child's sociometric status[J]. Developmental Psychology, 1992, 28(5):925-932.
[3] EISENBERG N , FABES R A, Murphy B, et al. The relations of children's dispositional empathy-related responding to their emotionality, regulation, and social functioning[J]. Developmental Psychology, 1996, 32(2):195-209.

[4] HAMPSON, ROBERT B . Adolescent prosocial behavior: Peer-group and situational factors associated with helping[J]. Journal of Personality and Social Psychology, 1984, 46(1):153-162.

[5] RAVIV, BAR-TAL, AYALON, et al. Perception of giving and receiving help by group members[J]. Representative research in social psychology, 1980, 11:139150 .

[6] FLOURI E, BUCHANNAN A, BRWAM V. Adolescents'perceptions of their fathers'involvement: Significance to school attitudes[J] .Psychol School, 2002, 39 (5): 575-580.

[7] ALDOUS J, MULLIGAN GM .Fathers' child care and children's behavior problems: a longitudinal study [J]. J Fam Issues,2002,23(5):623-647.

[8] LUNDAHL BW, TOLLEFSON D, RUSSER H, LOVEJOY CM.A meta-analysis of father involvement in parent training [J]. Res Soc Work Prac,2008,18(8):97-106.

[9] BANDURA A. Aggression: A social learning analysis[M]. NJ: PrenticeHall,1973.

[10] EGELAND B. Current controversies on family violence[M].Newbury Park NJ: Sage,1993:197-208.

[11] BRONFENBRENNERU. The ecology of human development: Experiments by Nature and Design[M]. Cambridge:Harvard University Press,1979.

[12] MINUCHIN P.Families and individual development:Provocations from the field of family therapy[J].Child Development,1985,56(2):289-302.

[13] Daring,N.\&Steinberg, L.Parenting style as context:An integrative model.Psychological Bulletin,1993,113:487 496.

[14] Glenn N D. . Quantitative Research on Marital Quality in the 1980s: A Critical Review. Journal of Marriage \& Family[J].1990,52)4):818-831.

[15] Minuchin S.Families and family therapy[M].Havard University Press, 1974.

[16] Belsky J,Putanm S,Crnic K.Coparenting,parenting,and early emotional development[J].New Directions for Child and Adolescent Development,1996(74):45-55.

[17] WERREN J H , PULLIAM H R .An intergenerational transmission model for the cultural evolution of helping behavior[J]. Human Ecology, 1981, 9(4):465-483.

[18] KNAFO A , PLOMIN R . Parental discipline and affection and children's prosocial behavior: genetic and environmental links[J]. Journal of Personality \& Social Psychology, 2006, 90(1):147-64.

[19] KNAFO A ,ISRAEL S.Genetic and environmental influences on prosocial behavior[M].Washington DC:Mikulincer and P R Shaver des,2010:149-167.

[20] EGELAND B. Current controversies on family violence[M].Newbury Park NJ: Sage,1993:197-208.

[21] MULLER R T , HUNTER J E, STOLLAK G. The intergenerational transmission of corporal punishment: a comparison of social learning and temperament models[J]. Child Abuse \& Neglect, 1995, 19(11):1323-1335.

[22] KELLY, JEFFREY A. Treating child-abusive families : intervention based on skillstraining principles[M].New York: Plenum Press, 1983.

[23] SAUL ROSENTHAL S, FEIRING C,LEWIS M. Political volunteering from late adolescence to young adulthood : Patterns and predictors[J]. Journal of Social Issues, 1998,54:477-493.

[24] BOONE C, DECLERCK C, KIYONARI T. Inducing cooperative behavior among proselfs versus prosocials: The moderating role of incentives and trust[J]. Journal of Conflict Resolution, 2010,54(5):799-824.

[25] MCHALE J P . Overt and covert coparenting processes in the family[J]. Family Process, 1997, 36(2):183-201.

[26] DAVIES P T,WOITACH D M J . Children's emotional security in the interparental relationship[J]. Current Directions in Psychological Science, 2008, 17(4):269-274.

[27] MCHALE J,IRACE K.Coparenting in diverse family system[M].Washington: American Psychological Association,2011:15-37.

[28] BELSKY J, CRNIC K, GABLE S. The determinants of coparenting in families with toddler boys: Spousal differences and daily hassles[J]. Child Development, 1995,66: 629-642.

[29] GARNER P W. Toddlers' emotion regulation behaviors: The roles of social context and family expressiveness[J]. The Journal of Genetic Psychology, 1995,156:417430.

[30] BOLGER N , DELONGIS A, WETHINGTON K E . The contagion of stress across multiple roles[J]. Journal of Marriage \& Family, 1989, 51(1):175-183. 